\title{
Museologi SOM VETENSKAPLIGT FÄLT
}

\section{Bengt Lundberg}

I somras hade vi våra franska vänner på besök. Vi brukar träffas vartannat eller vart tredje år, ofta för att åka skidor tillsammans eller bara för att umgås - men $i$ àr var det annorlunda. Den svenska kulturen var sommarens projekt och jag skulle skjutsa dem med bil till och genom den. Vår utgångspunkt var Höga Kusten, sedan siktade vi ner mot Dalarna, vidare mot västkusten för att sedan inta huvudstaden. Vi aker forbi och stannar vid åtskilliga av de natur-och kulurmiljöer, som ger innehall àt klyschan "Sverige är fantastiskt». Men varje gång vi passerar en sevärdhet inträffar samma händelsekedja ${ }^{1}$ :

Jag annonserar i god tid märkvärdigheten: - Till vänster kommer ni snart att se Skuleberget!

Vilket omedelbart leder till att de kastar sig ner i sina franska resehandböcker över Sverige $\mathrm{i}$ ett intensivt läsande om den sevärdhet vi just passerar. Alternativt kunde de ge kulturbegivenheten en flyktig blick för att därefter kasta sig in i en häftig diskussion om någon detalj de uppfångat. Ofta drogs jag in i dessa diskussioner vilket resulterade i många extramil av felkörningar, p.g.a. the linguistic turn.

Detta var en kulturkrock. Det som för mig var självklara skönhetsvärden, som var historiskt intressant eller fascinerade mig på annat sätt vid direkt betraktande - det lämnade dem till synes oberörda. Först när de läst eller diskuterat eller pressat ur mig en ordmässig redogörelse till yttersta gränsen av mitt vetande föreföll de nöjda.

Samma sak upprepade sig när vi besökte museer. De passerade genom museisalarna inneslutna $i$ en språkbubbla, som åtminstone för mig - såg ut att skymma deras sikt. Detta ledde mina tankar till Michel Foucaults installationsföreläsning från 1970, då han bl.a. yttrade:

Bakom mig ville jag höra en röst (som tagit till orda för länge sedan och i förväg sagt allt jag kommer att säga) tala så här: «Måste fortsätta, kan inte fortsätta, måste fortsätta, måste säga ord så länge de finns, måste säga dem ända tills de finner mig, ända tills de säger mig - sällsamma smärta, sällsamma fel, måste fortsätta, kanske är det redan gjort, de har kanske redan sagt mig, kanske har de burit mig ända fram till tröskeln av min historia, fram till dörren som öppnar sig mot min historia» ${ }^{2}$. 
40 Våra franska vänner bekräftade på ett slående sätt Foucaults tes att vi är inskrivna i och underkastade diskursens ordning, samtalsordningar som bär och uttrycker oss utan att vi riktigt kan värja oss. Den dörr som öppnade sig mot historien (som Foucault talade om) - den var deras egen franska historia i bemärkelsen kulturarv, erfarenheter, minnen och beteenden som de bar med sig - som ett osynligt museum. Det svenska kulturarvet, de svenska landskapen och de svenska tingen teg - ända tills de med språkets hjälp gjorts till franska.

Det här sommarminnet pekar på ett antal områden som är centrala i museologisk forskning och i museologiskt arbete: Samla - Vårda - Visa - Forska.

Samla är det bokstavliga hopförandet av bevaransvärda föremål, men hit hör också den process som gör något bevaransvärt. Även utpekandet och utmärkandet av vad som anses vara bevaransvärda natur- och kulturmiljöer får anses höra till samlandet. Bakom dessa processer finns ett stort antal aktörer, från hängivna hembygdsälskare, turistintressen och företagare, professionella kulturarvsaktörer, som museifolk m. fl. som utväljer vissa saker eller platser till att vara sevärdheter, mera sällan hörvärdheter, luktvärdheter, smakvärdheter eller kännvärdheter för att anknyta till de andra sinnena.

Vårda. Om samla «rätt» är svårt så är vårda rätt också ett bekymmer. Om vård är möjlig överhuvudtaget, när en ständig nedbrytning pågår. Den nyligen genomförda satsningen på «Vårdberget», dvs. de mängder av icke-vårdade föremål som "väntade» på vård och som väl $\mathrm{i}$ viss mån fick vård, är ett exempel som aktualiserade problematiken.
Visa är naturligtvis den del av museernas verksamhet som besökarna kommer i direkt kontakt med via utställningar. Detsamma gäller de kulturmiljöer som utnämnts till kulturarv och som med olika tekniker - ofta skyltar eller kartor - visas fram för potentiella och verkliga besökare.

Den riktigt goda utställningen eller kulturmiljön har en inbyggd museipedagogik, men så goda utställningar eller miljövisningar finns inte att de inte blir bättre med en god museipedagog. Min kollega Peter Lundqvist här på institutionen, som ofta uttrycker sig drastiskt, brukar säga att

vilken skitutställning som helst kan bli bra med en duktig museipedagog.

Museipedagogiken är ett eftersatt område med små resurser och låg status. Detta kan en normativ museologi ändra.

Forska läggs ibland till i denna verksamhetsbeskrivning som formeln SamlaVårda-Visa utgör när det gäller kulturarvsområdet. Forskning i museerna görs i liten utsträckning och den forskning som bedrivs gäller huvudsakligen de egna samlingarna.

Men framför allt kommer forskningen in i museerna via den akademiskt utbildade personal som fått sin undervisning baserad på forskning. De ämnen som länge dominerat vid universitetsutbildning till museitjänsteman har varit arkeologi, etnologi och konstvetenskap - och samma perspektiv fortsätter att prägla museernas organisation. Man annonserar efter en arkeolog eller etnolog när tjänster blir lediga och dessa ämnesperspektiv präglar hela verksamhetskedjan: samla - vårda visa - forska. Minst påverkas antagligen vårda-länken, där konservatorsutbildning $\mathrm{i}$ 
bästa fall ligger till grund. Detta är naturligtvis ett centralt museologiskt fält att studera. Vad betyder den grundläggande utbildningen? Hur utvecklas ny kunskap hos de anställda? Hur gammal är grundutbildningen i genomsnitt inom museimannakåren? Får de anställda möjligheter till fort- och vidareutbildning?

Om inte vad blir konsekvenserna?

\section{KVL OCH MUSEOLOGI I UMEA}

Sedan snart 20 år har ytterligare ett ämne tillförts museimannautbildningen. År 1981 togs de första studenterna in på KVL (kulturvetarlinjen) i Umeå. De läste en baskurs första terminen, som från 1988 när institutionen för museologi bildades, då blev en A-kurs i ämnet. Den s.k. sjätte terminen blev B-kurs. Om vi ser historiografiskt på denna vår institutions utveckling så kan man nog påstå att dessa till stor del yrkesutbildande kurser byggde på en lång museografisk tradition med rötter i 1500-talet. Samuel Quicchebergs traktat Museum sive theatrum från 1565 är en sorts startpunkt för denna handbokstradition - med råd om hur samlingar skall komma till, klassificeras och ställas ut. Den vittnar om en museologi, som utvecklats inifrån muserna. Dessa handledningar blir vanligare under 1700 - och 1800-talen. Ordet museologi nämns första gången $\mathrm{i}$ en tysk tidskrift från 1877 , Zeitschrift für Museologie und Antiquitätenkunde, Dresden.

Den moderna museologins portalgestalt Georges Henri Rivière, som kanske mest är känd för Musée des Arts et Traditions Populaire (ATP) och för ekomuseiidén, kom in från ett helt annat håll. Han var musikutbildad och var bl.a. en framståen- de pianist som ackompanjerat Josephine Baker. Rivière startade berömda kurser i museologi vid Sorbonne-universitetet. Här ser vi för första gången en ansats till ett självständigt akademiskt ämne skilt från museiinstitutionerna.

Internationellt utvecklades museologin starkt från 1960-talet sannolikt påverkad av den stora demokratidiskussionen under detta årtionde. För Sveriges och Nordens del är grundandet av tidskriften Nordisk Museologi 1993 av största betydelse för utvecklandet av ett museologiskt forskningsfält. Genom att göra en innehållsanalys av artiklarna i tidskriften -2 nummer per år under nu 7 år - kan forskningsfältets fokus och yttergränser ringas in.

\section{NORDISK MUSEOLOGI - 180 TEXTER}

Utav de cirka 180 artiklar som hittills publicerats i tidskriften handlar drygt 70 om just museet som fenomen och institution. Det är den helt dominerande innebörden i museologi enligt tidskriften museet som sådant. ${ }^{3}$ Ofta ges en precisering av att det handlar om det arkeologiska museet, konstmuseet och inte minst ekomuseer som ofta diskuteras i Nordisk Museologi. Utav kategorierna samla, vårda, visa så representeras samla och visa av ett knappt tjugotal artiklar vardera, medan vårda inte alls nämns - åtminstone inte av rubrikerna att döma. Kulturarv får ett tiotal noteringar och museologi och explicit forska har fått få rubriker - endast fem resp. två. Sedan finns en relativt stor övrigkategori, som kan rymma idéhistoriska perspektiv, personer, internet och dylikt. Eller vara en roande, men svårplacerad, rubrik, t.ex. Eva Perssons: «Hellre en nybadad 
42 syndare än trenne rättfärdiga med fotsvett», som handlar om att återföra museernas föremål och vetande till verkligheten via konsten. Förhållandevis litet finns om museipedagogik, reception och utbildning, som ger stoff till cirka tio artiklar sammanlagt. Museologi blir alltså enligt den här sammanställningen studiet av och läran om museet.

Om man sen tittar på teoretiska inspiratörer i referenserna så intar utan tvekan Foucault och hans lärjungar huvudrollen. Även Kenneth Hudson bör nämnas som en självständig museologisk inspiratör som ständigt krävde människan i centrum.

Tidskriftens - och ämnets - målsättning är dock vidare. Redaktören, Per-Uno Ågren, gör en programförklaring i det första numret, som lyder så här:

Museologin studerar hur det museala objektet konstitueras, vilka värderingar och beslut som styr den museala processen från urval och insamling till visning och förmedling och därmed vilken historiebild, kulturuppfattning och natursyn som projiceras i skyddade objekt och miljöer: alltså människans förhållande till sin fysiska omvärld som historia.

Forskningsfältet rymmer alltså betydligt mer än själva museet. Ämnets avgränsning sträcker sig långt utanför museets väggar. Per-Uno Agren tar upp tre teoretiska huvudperspektiv inom museologin: ett historiskt, som söker beskriva och förstå natur- och kulturarv vid en viss tid och på en viss plats; ett sociologiskt som studerar de beteenden, verksamheter och institutioner som blivit en följd av föreställningen om ett natur- och kulturarv; ett kommunikativt som gäller miljöarvets förmedling $\mathrm{i}$ tid och rum.

\section{ETT ÖVERGRIPANDE PERSPEKTIV}

Ett försök till ett mer övergripande perspektiv på vad det museologiska forskningsfältet kan vara, har jag nyligen gjort $\mathrm{i}$ den andra tidskrift som utges vid institutionen för kultur och medier, Kulturella Perspektiv $\mathrm{Nr} 2$, 2000. I artikeln Under toppen av ett isberg diskuterar jag det museologiska forskningsfältet $\mathrm{i}$ tid och rum.

Fältet illustreras grafiskt på vidstående sida. I figuren representerar den översta triangeln två betydelser:

1. Den visar den semiotiska triangeln, dvs. hur språk och tecken förhåller sig till tänkandet (föreställningar) och till erfarenheter som är delar av den verklighet vi uppfattar (referenten).

2. Den symboliserar också nuet. Med det absoluta nuet där vi alltid befinner oss i triangelns övre spets, men där hela den övre triangeln visar något som jag kallar det utsträckta nuet, som kan vara en 25 minuters föreläsning. Det kan också vara det senaste decenniet eller rent av det som ibland kallas den lilla tiden - av människan upplevd tid. I motsats till den stora tiden - kosmisk tid - en tid som finns oberoende av oss människor och våra upplevelser.

Den stora kosmiska tiden för ner till «under toppen av isberget» Här finns all förfluten tid. Under en del av denna tid en liten del - har människan funnits med. Och med människan kommer förvandlingen av stora delar av naturen till kultur. Det är dels en omvandling av människan själv från naturvarelse till alltmer kulturvarelse - civilisationsprocessen om man så vill. Dels är det människans omvandling av naturlandskapet till kulturlandskap. 
(t. ex. forestallning om hus)

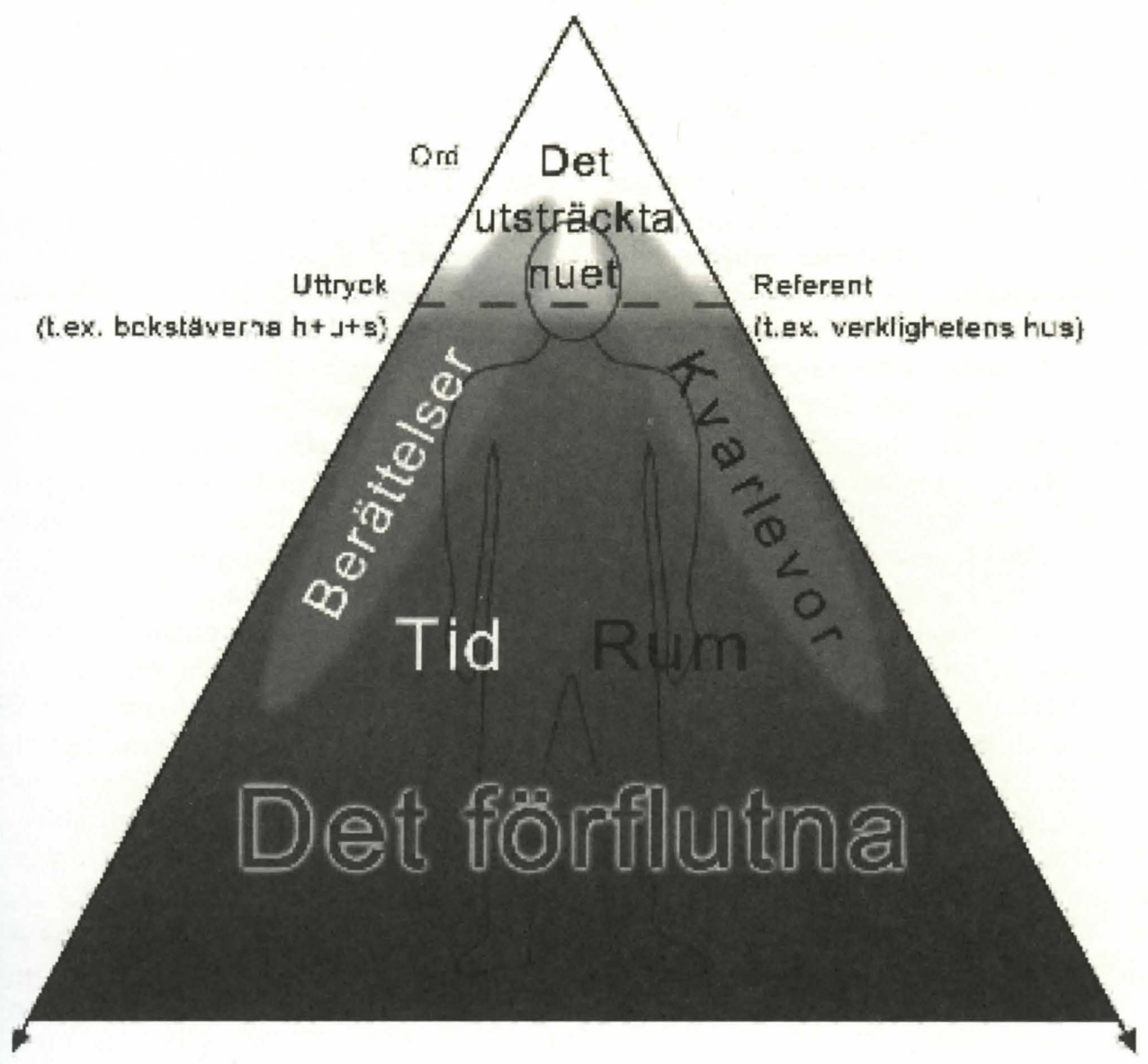

Musei- och kulturmiljöverksamhet handlar självklart mycket om det rum som omger människan och som människan levat av och i - och där vi också nu lever i och av detta rum eller denna miljö. Det är därför människan är inskriven i triangeln - «isberget».

Samma rum styr museer och kulturmil- jöorganisation, eller snarare rumsuppdelningen, mer än tiden. Museer får områdes- eller rumsbetecknande namn: Västerbottens museum, Nordiska museet, Landskrona museum, Stockholms Stadsmuseum osv. Även kulturmiljövården med riksantikvarie för hela landet och länsantikvarier för länen och kommunalt kultur- 
44 miljöansvar faller in i en gammal svensk förvaltningstradition från 15-, 1600-tal, med tre nivåer: riks-, läns- och lokalnivå.

Sedan finns mer ämnespecifika områden som Armémuseum, Musikmuseet, Postmuseet, eller rena personmuseer som Andrémuseet och Strindbergsmuseet. Det vanligaste är dock att rummet är styrande princip. Tiden finns i vissa fall med som namngivare, t.ex. Moderna museet eller Medeltidsmuseet.

Oavsett om det nu är ett museiföremål eller ett helt kultur- eller naturlandskap, så är dessa rumsliga och hör då hemma $\mathrm{i}$ figurens högra del - men det finns nästan alltid en koppling mellan de berättelser, som i figuren ligger till vänster och de materiella kvarlevorna.

En avgörande skillnad mellan figurens vänstra del, berättelserna, och den högra, kvarlevorna, är att berättelserna, t.ex. skriven historia, ofta anger tid, dag eller årtal och därmed möjliggör ett kronologiskt perspektiv. Kvarlevorna i den högra delen av figuren är normalt odaterade. Det står inget årtal på berget, skogen eller stenyxan, men vetenskap som vilat på skriftlig grund som geologi, dendrokronologi, arkeologi kan ge upplysningar om tid. Men primärt är denna del rumslig och materiell.

\section{EN HUVUDUPPGIFT}

Den museologiska forskningens huvuduppgift, som jag ser det, är att knyta samman eller överbrygga motsättningen mellan berättelser och kvarlevor. De är bara skilda uttryck för ett gemensamt förflutet. Jag ska ge ett exempel på en sådan koppling.

Den 14 maj 1931 avlossades skotten i
Ådalen. Svensk militär hade utkommenderats till skydd för strejkbrytare i Lunde vid Ångermanälven. Ett demonstrationståg med tusentals protesterande arbetare besköts och 5 människor miste livet.

Massakern kunde blivit ännu värre om inte en rådig trumpetare blåst signalen ELD UPPHÖR!

En trumpet finns kvar som påstås ha använts vid detta tillfälle. Om detta påstående är sant så möts den skrivna historien och den materiella historien här, just i denna trumpet. Ådalsskotten är ett ett s.k. formativt moment, dvs. en sorts avgörande ögonblick eller vändpunkt. Ådalsskotten ses av historiker som en av de viktigaste orsakerna till att socialdemokratin kom till makten för lång tid framåt.

Trumpeten är knuten till en plats Ådalen - och har regementsinsignier. Den är tillräckligt gammal för att kunna ha varit med och det finns en berättelse anknuten till just denna. Samtidigt finns berättelsen om ELD UPPHÖR inskriven i den stora historien. Tid och rum möts. En källkritisk utredning kring trumpeten pågår.

Hur har då denna trumpet hamnat $\mathrm{i}$ min hand? Den har köpts på en loppmarknad. Dessa loppmarknader, antikhandlare, STV:s Antikrunda m.m. visar på ett växande intresse för gamla föremål. En hel marknad för materiell kultur har uppstått, särskilt under det senaste decenniet.

Det finns en anekdot, förmodligen bekant för de flesta, men jag avslutar med den, eftersom den kan problematisera det museologiska forskningsfältet.

Det är natt. En man ligger och kryper på alla fyra under en gatlykta. Han är väl inte helt nykter. Då kommer en polis fram och ställer frågan: 


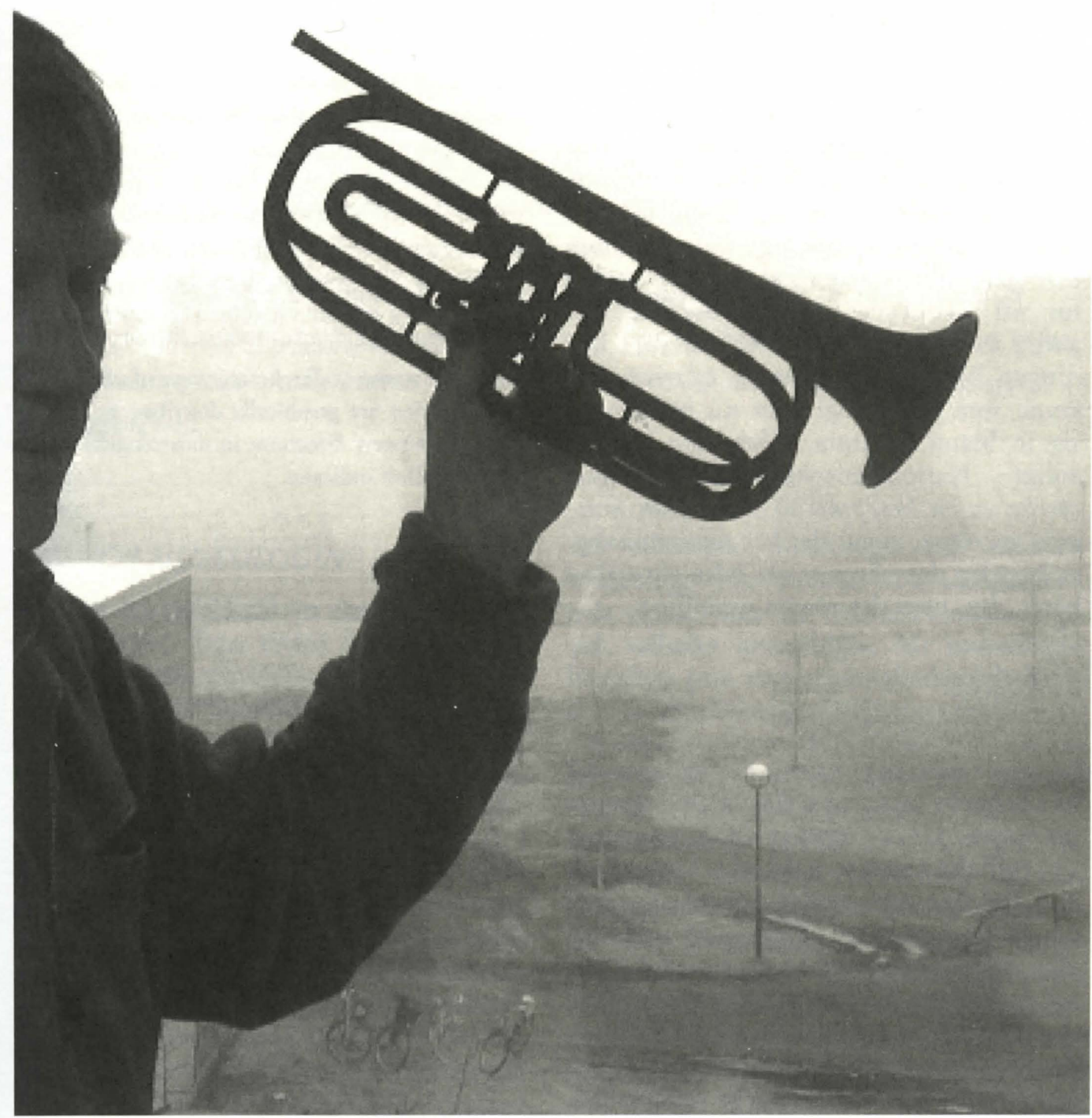


46 - Och hur var det här då?

- Jag letar efter mina nycklar.

- Har ni tappat dom här då?

- Nej men det är bara här jag ser att leta.

Kanske borde vi söka de "museologiska nycklarna " utanför de upplysta museirummen ute i kulturskymningens landskap.

Och vem var polisen egentligen? Jag tror faktiskt det är Foucault. Han skulle inte tyckt om själv - tror jag - att inta en sådan position. Vi bör nog befria honom och själva försöka utveckla teorier istället för att deducera utifrån Foucault och andra storheter. Abduktion kan vara lösningen för ett åtminstone relativt nytt ämne som museologi som nu bör tränga sig in bland de stora. Abduktion betyder enligt Nationalencyklopedins ordbok rörelse av en kroppsdel àt sidan frän kroppens mittlinje, men i det här sammanhanget betyder det närmast att lyfta sig själv i håret, dvs. göra det nästan omöjliga.

\section{SUMMARY}

Museology and its field of research

During an excursion to Swedish historical sites with friends from France the author observes how his companions had to transform their impressions into a verbal discourse with the aid of a printed guide before they were satisfied. Just taking a good look at the monument or contenting themselves with what they were told by their Swedish friend was not enough. In doing this the French guests confirmed in a striking way Foucault's statement that we are inscribed in the order of one of the discourses at our disposal and that we are subordinated the cultural heritage, the memories and experiences we carry along like an invisible museum. The
Swedish scenery, monuments and objects did not communicate a meaning until they had been verbally translated into French.

The basic formula for the museum process is inscribed in the standard programme for museum studies - collect, preserve, exhibit. Less prominent is museological research although it can be traced as far back as the 16th century. The introduction of the journal Nordisk Museologi in 1993 has however been important in establishing a forum for research concerning theoretical issues. In the seven years of its existence 180 articles have been published, of which 70 deal with the museum institution as a phenomenon, 20 with collecting and 20 more with exhibitions. The concept of heritage is treated in 10 articles and a few are concerned with preservation, personalities, internet etc.

The potential wider perspectives of the idea of musealization are graphically described by the author and the new directions in museological studies and research it indicates.

\section{NOTER}

1 Texten återger en föreläsning 21 september 2000 i Umeå.

2 Michel Foucault, Diskursens ordning (sv övers. 1971; Stockholm/Stehag, 1993), s $5 \mathrm{f}$.

3 Kvantifieringen har skett utifrån rubriceringen som ju bör innehålla artikelns fokus

Bengt Lundberg är docent och forrestår avdelningen för museologi vid institutionen for kultur och medier, Umea universitet.

Adr. Institutionen for kultur och medier, Umeå universitet, S-901 87 Umeå.

Fax +4690166672

e-post Bengt.Lundberg@kultmed.umu.se 